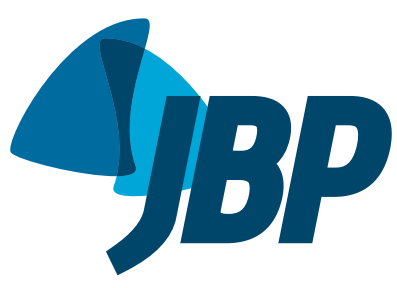

1. Programa de Pós-Graduação em Ciências Farmacêuticas, Faculdade de Farmácia, Universidade Federal do Rio Grande do Sul - UFRGS Porto Alegre (RS) Brasil.

2. Laboratório de Pesquisa em Resistência Bacteriana, Centro de Pesquisa Experimental, Hospital de Clínicas de Porto Alegre - HCPA Porto Alegre (RS) Brasil.

3. Universidade Federal do Pampa UNIPAMPA - Uruguaiana (RS) Brasil.

4. Laboratório Central de Saúde Pública do Rio Grande do Sul - LACEN/RS Porto Alegre (RS) Brasil.

5. Hospital Sanatório Partenon, Porto Alegre (RS) Brasil.

a. (ID) http://orcid.org/0000-0002-0786-8190

b. (iD) http://orcid.org/0000-0003-3437-0256

c. (iD http://orcid.org/0000-0001-8055-7658

d. iD http://orcid.org/0000-0003-1552-5275

e. (iD http://orcid.org/0000-0002-7969-3908

f. (iD http://orcid.org/0000-0001-8440-8561

Submitted: 18 June 2017.

Accepted: 15 October 2017

Study carried out in the Ambulatório de

Referência de TBDR e MNT, Hospital

Sanatório Partenon, Porto Alegre (RS) Brasil.

\title{
Nontuberculous mycobacterial lung disease in a high tuberculosis incidence setting in Brazil
}

\author{
Maiara dos Santos Carneiro',2,a, Luciana de Souza Nunes ${ }^{2,3, b}$, \\ Simone Maria Martini De David ${ }^{4, c}$, Claudia Fontoura Dias ${ }^{5, d}$, \\ Afonso Luís Barth ${ }^{1,2, e}$, Gisela Unis ${ }^{5, f}$
}

\begin{abstract}
Objective: The incidence of lung disease caused by nontuberculous mycobacteria (NTM) has been increasing worldwide. In Brazil, there are few studies about nontuberculous mycobacterial lung disease (NTMLD), and its prevalence is yet to be known. Our objective was to determine the specific etiology of the disease in the state of Rio Grande do Sul, Brazil, as well as the frequency and diversity of NTM species in our sample of patients. Methods: This is a retrospective analysis of the medical records of patients diagnosed with NTMLD treated in a referral center located in the city of Porto Alegre, Brazil, between 2003 and 2013. Results: Our sample comprised 100 patients. The most prevalent NTM species were Mycobacterium avium complex (MAC), in 35\% of the cases; $M$. kansasii, in 17\%; and $M$. abscessus, in 12\%. A total of 85 patients had received previous treatment for tuberculosis. Associated conditions included structural abnormalities in the lungs, such as bronchiectasis, in $23 \%$ of the cases; COPD, in 17\%; and immunosuppressive conditions, such as AIDS, in 24\%. Conclusions: MAC and M. kansasii were the most prevalent species involved in NTMLD in the state, similarly to what occurs in other regions of Brazil. Data on regional epidemiology of NTMLD, its specific etiology, and associated conditions are essential to establish appropriate treatment, since each species requires specific regimens. Most patients with NTMLD had received previous tuberculosis treatment, which might lead to development of resistance and late diagnosis.
\end{abstract}

Keywords: Nontuberculous mycobacteria; Mycobacterium infections, nontuberculous; Lung diseases.

\section{INTRODUCTION}

Nontuberculous mycobacteria (NTM) consist of species of the genus Mycobacterium, but with distinct characteristics from those of the species of the Mycobacterium tuberculosis complex. ${ }^{(1)}$ Since NTM are widespread in nature, it is believed that the source of infection in humans is the environment. ${ }^{(2)}$ Infections caused by NTM are not considered a public health problem, and, therefore, reporting them is not mandatory, even though a few species are highly pathogenic and responsible for causing disease and death. ${ }^{(3)}$

The propensity of NTM to cause lung disease is greater in the presence of associated factors, such as COPD, previous tuberculosis, cystic fibrosis, bronchiectasis, $\mathrm{HIV}$, and transplantation. It is known that pre-existing structural lung abnormalities and immunosuppressive conditions favor the development of NTM lung disease (NTMLD). ${ }^{(4)}$

Worldwide, NTM have been increasingly identified as causative agents of lung disease, ${ }^{(3)}$ with high incidence and prevalence rates, including all regions in the USA (the annual prevalence significantly increased from 20 cases/100,000 population in 1997 to 47 cases/100,000 population in 2007 , i.e., $8.2 \%$ per year), southwestern Ireland (mean incidence of $0.4 / 100,000$ population), New Zealand (incidence of $1.92 / 100,000$ population), and Canada (mean incidence of $6.7 / 100,000$ population). ${ }^{(5-8)}$

At least 40 species of NTM are associated with lung disease, ${ }^{(9)}$ the lungs being the most common site affected by NTM. The clinical diagnosis of NTMLD is complicated by symptom similarity with other lung diseases, especially tuberculosis. The wide variety and nonspecificity of symptoms caused by NTMLD, such as cough, hemoptysis, chest pain, fever, asthenia, weight loss, shortness of breath, and night sweats, hinders the diagnosis. NTMLD requires specific diagnosis to define the therapeutic regimen, given that different species of NTM require distinct therapies. ${ }^{(10-12)}$

In the state of Rio Grande do Sul, the southernmost Brazilian state, mycobacterial cultures are not performed as a routine procedure for the diagnosis of tuberculosis,

Correspondence to:

Gisela Unis. Hospital Sanatório Partenon, Ambulatório de Referência de TBDR e MNT, Avenida Bento Gonçalves, 3722, CEP 90650-000, Porto Alegre, RS, Brasil. Tel.: 5551 3336-8772. E-mail: giselaunis@gmail.com

Financial support: None. 
which further hinders the detection of NTM. Since there is no mandatory reporting of NTMLD cases and there are no studies on NTMLD in the state, the main objective of the present study was to determine the specific etiology of the disease in our state, as well as the frequency and diversity of NTM species.

\section{METHODS}

The present study involved patients attending the Tuberculosis/NTM Outpatient Clinic in Hospital Sanatório Partenon (HSP), the referral institution for the treatment of multidrug-resistant tuberculosis and NTM-related diseases in the state of Rio Grande do Sul, Brazil. In accordance with the Brazilian Ministry of Health guidelines, ${ }^{(13)}$ mycobacterial cultures should only be performed according to the following criteria: 1) patients who were diagnosed with tuberculosis who remain positive for AFB at the second month of treatment; 2) patients with previously treated tuberculosis and a positive result for AFB; 3) patients who are contacts of people diagnosed with drug-resistant tuberculosis; and 4) patients taking part of specific population groups considered at risk, such as health professionals, homeless people, those deprived of liberty, indigenous populations, and people living with HIV. Patients with suspected NTMLD in the state of Rio Grande do Sul are sent to the HSP Outpatient Clinic for evaluation, diagnosis, treatment, and follow-up.

To demonstrate the clinical profile of patients with NTMLD, a retrospective review of the clinical medical records from the HSP Outpatient Clinic regarding tuberculosis and NTMLD was performed. The study population consisted of all patients who presented with pulmonary symptoms, had radiological findings consistent with mycobacterial disease, had an NTMpositive respiratory culture, and were treated at the HSP Outpatient Clinic between 2003 and 2013.

In accordance with an official statement by the American Thoracic Society (ATS)/Infectious Diseases Society of America (IDSA), (11) the diagnosis of NTMLD should be based on respiratory symptoms, image findings (e.g., nodular or cavitary opacities on X-rays or multifocal bronchiectasis and multiple small nodules), and a positive culture for NTM in two or more sputum specimens or in one BAL fluid specimen. Lung biopsy followed by a positive tissue culture is another way to confirm the diagnosis. ${ }^{(11)}$

Cure was defined when a patient presented with 12 consecutive negative cultures collected every month (bacteriological cure). In cases of absence of expectoration, cure was clinically and radiologically diagnosed after 18 months of treatment (clinical cure). (11) Patients were followed up for 2 years after the end of treatment for the identification of relapse prior to defining the outcome as definitive cure. Since there is no reliable antibiotic regimen to provide cure for M. abscessus lung disease, the disease is considered to be controlled when no exacerbations are observed for 2 years. ${ }^{(11)}$
Demographic, clinical, and epidemiological data, including associated diseases, treatment outcome, and previous tuberculosis treatment, were obtained from medical records. Patients with extrapulmonary mycobacteriosis and patients younger than 18 years of age were excluded from the study.

The identification of NTM species is performed by the association of phenotypic and molecular tests. After growth on a solid medium, colonies are tested for phenotypic differentiation between $M$. tuberculosis complex and NTM. The molecular identification is performed by PCR-restriction enzyme analysis, which is based on the amplification of a 441-bp fragment of the $h s p 65$ gene and subsequent digestion with two restriction enzymes (BstEII and HaeIII). ${ }^{(14,15)}$

The descriptive analysis was expressed as mean \pm SD or proportion. The study was approved by the Research Ethics Committee of the Escola de Saúde Pública/Secretária de Saúde - ESP/SES/RS (CAAE no. 18656413.1.3001.5312).

\section{RESULTS}

Our sample comprised 100 patients who met the inclusion criteria. The mean age of the patients was 54.6 years, and 24 patients had positive HIV results. Most (64\%) of the patients reported pulmonary and systemic signs and symptoms of the disease, including cough, hemoptysis, chest pain, fever, anorexia, weight loss, shortness of breath, and night sweats (Table 1).

The most common associated conditions were HIV, in $24 \%$ of the patients; bronchiectasis, in $23 \%$; and COPD, in $17 \%$. No associated disease was identified in $23 \%$ of the patients (Table 2 ). In our sample, at least 42 patients presented with structural abnormalities of the lungs. A total of 85 patients had received previous treatment for tuberculosis, based on a positive AFB smear (Table 1).

A total of 74 patients met the criteria for NTMLD in accordance with the ATS/IDSA ${ }^{(11)}$ statement (Table 1 ). We were able to identify an increase in the number of patients with NTMLD disease from 2007 to 2013 (Figure 1).

Among all of the species of NTM identified, three were the most prevalent (in $64 \%$ of the cases): $M$. avium complex (MAC), in 35 patients; M. kansasii, in 17; and M. abscessus, in 12. Among MAC species, 26 were identified as $M$. avium, and 9 were identified as $M$. intracellulare. Rapidly growing mycobacteria were identified in only 16 patients: M. abscessus, in 12; and $M$. fortuitum, in 4 . However, we were unable to identify the NTM species in 26 patients (Table 3 ). In addition, we were also unable to determine the most prevalent NTM species with regard to the HIV status of the patients, because the species were unidentified in 15 of the 24 patients diagnosed with HIV.

The cure rate of the patients who met the ATS/IDSA criteria $^{(11)}$ was $60.7 \%$ and $73.3 \%$ in those infected with MAC and M. kansasii, respectively. In addition, 
M. abscessus lung disease was considered controlled in $70.0 \%$ of those cases. Of the 17 patients diagnosed with $M$. kansasii infection, $13(76.4 \%)$ received a treatment regimen with rifampin, isoniazid, and ethambutol, whereas $67.7 \%$ of the patients infected with MAC were treated with a regimen with rifampin, ethambutol, and clarithromycin, and $41.6 \%$ of those infected with $M$. abscessus were treated with a regimen containing amikacin, clarithromycin, and imipenem.

\section{DISCUSSION}

The increasing number of cases and the diversity of species found in the present study demonstrate that NTMLD requires more attention. In fact, the real prevalence of NTMLD is possibly underestimated, since there is no mandatory reporting of cases of NTM disease in Brazil. Moreover, the vast majority of routine laboratories do not perform cultures for mycobacteria but only the evaluation of AFB direct smears.

The increase in the number of cases of NTMLD from 2007 to 2013 might be related to an increasing

Table 1. Clinical and demographic characteristics of the patients with nontuberculous mycobacterial lung disease $(N=100) .^{a}$

\begin{tabular}{lc}
\hline \multicolumn{1}{|c}{ Characteristic } & Result \\
\hline Male gender & $51(51)$ \\
HIV positive & $24(24)$ \\
Age according to HIV status, years & \\
$\quad$ HIV positive & $43.6 \pm 11.9$ \\
$\quad$ HIV negative & $56.2 \pm 15.3$ \\
$\quad$ Not informed & $64.1 \pm 16.3$ \\
Symptoms & \\
$\quad$ Lung & $17(17)$ \\
$\quad$ Systemic & $8(8)$ \\
$\quad$ Lung and systemic & $64(64)$ \\
$\quad$ Not specified & $11(11)$ \\
Previous tuberculosis treatment & $85(85)$ \\
Met the criteria for NTMLD & $74(74)$ \\
\hline
\end{tabular}

NTMLD: nontuberculous mycobacterial lung disease. aValues expressed as $\mathrm{n}(\%)$ or mean \pm SD. ${ }^{\text {IIn }}$ accordance with Griffith et al. ${ }^{(11)}$ awareness on the part of physicians regarding this issue, increasing the number of cases diagnosed; improved laboratory capacity; a higher number of people living with structural abnormalities in the lung or immunosuppressive conditions; and increased life expectancy. ${ }^{(3,11)}$

Brazil has a high prevalence of tuberculosis-30.9 cases/ 100.000 population in $2015^{(16)}$-which is highly contagious. Therefore, it is recommended that patients with AFB in sputum should be treated regardless of culture identification of the M. tuberculosis complex. Moreover, tuberculosis can result in pulmonary sequelae; therefore, patients who had tuberculosis show a higher risk of developing NTMLD. ${ }^{(17)}$ In the present study, most patients $(85 \%)$ had had a prior treatment for tuberculosis. Similar results were also found in the state of Rio de Janeiro (in $58 \%$ of the cases). ${ }^{(17)} \mathrm{A}$ limitation of the present study is that we were unable to identify whether NTMLD was due to tuberculosis sequelae because those patients who had been treated for tuberculosis had no culture confirmation.

Structural abnormalities, such as bronchiectasis, COPD, and cystic fibrosis, are considered risk factors

Table 2. Main coexisting medical conditions in the patients with nontuberculous mycobacterial lung disease $(N=100)$.

\begin{tabular}{lc}
\multicolumn{1}{c}{ Coexisting condition } & Patient \\
AIDS & 24 \\
None & 23 \\
Bronchiectasis & 22 \\
COPD & 17 \\
Cancer & 6 \\
Hepatitis B or C & 6 \\
Diabetes mellitus & 4 \\
Tuberculosis & 2 \\
Systemic lupus erythematosus & 1 \\
Transplant & 1 \\
Silicosis & 1 \\
Cystic fibrosis & 1 \\
Congenital immunosuppression & 1 \\
\hline
\end{tabular}

apatients may have more than one coexisting condition.

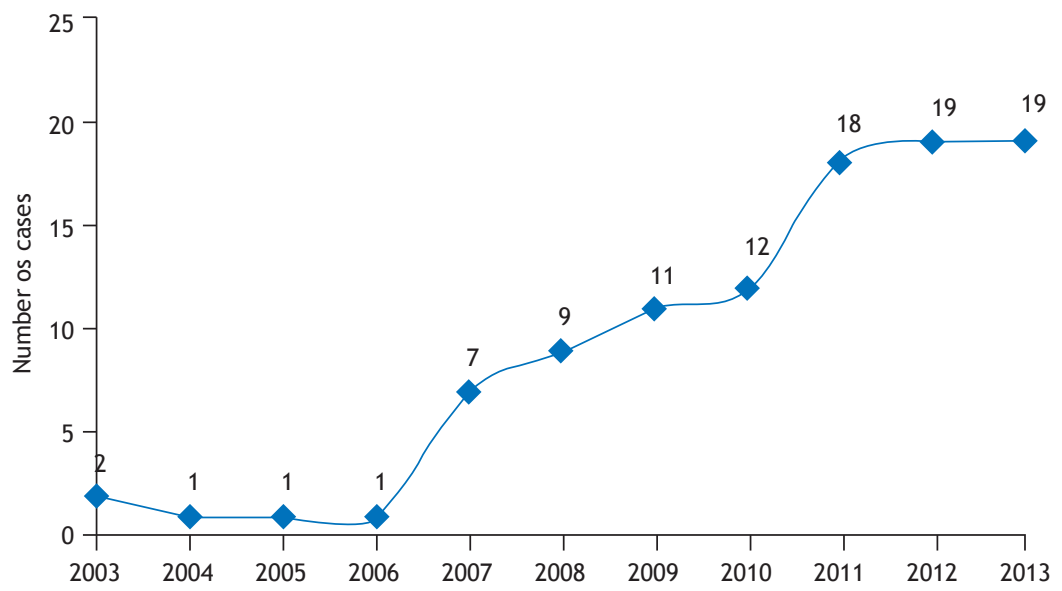

Figure 1. Number of nontuberculous mycobacterial lung disease cases per year $(N=100)$. 
for the emergence of NTMLD. In the present study, these conditions were prevalent; however, in some cases of patients with bronchiectasis, we were unable to determine whether NTMLD was a sequel of the pre-existing lung condition or whether it was the initial illness. ${ }^{(4)}$

Disease triggered by mycobacteria is common in people with AIDS and low CD4 counts. ${ }^{(18)}$ The state of Rio Grande do Sul has the second highest rate of HIV cases per capita (38.3 cases/100.000 population). ${ }^{(19)}$ This might have contributed to the increase in NTMLD cases in this group of patients.

The results of the current study indicate that MAC was the most common NTM causing lung disease in the state. A higher prevalence of MAC was also found in studies carried out in other countries, such as the USA, ${ }^{(20)}$ China, ${ }^{(21)}$ and Australia. (22) In contrast, at the Professor Hélio Fraga Referral Center in the state of Rio de Janeiro, de Mello et al. ${ }^{(17)}$ reported that 33.9\% $(59 / 174)$ of the patients with NTMLD were infected with M. kansasii.

In fact, Brazil exibits diversity in the prevalence of NTM species causing lung disease (Table 4). (17,23-25) $^{2}$ The NTM species most commonly found in clinical samples in industrialized countries are MAC and $M$. kansasii. ${ }^{(26)}$ Clinical and radiological signs of disease caused by M. kansasii are similar to those of postprimary tuberculosis, ${ }^{(27,28)}$ and this species responds to antituberculosis treatment, leading to the late identification or the lack of a diagnosis of that species. ${ }^{(17)}$ The most likely reason for the fact that NTMLD caused by MAC was more prevalent in the state of Rio Grande do Sul than in the state of Rio de Janeiro is the higher number of HIV-positive patients in the former state (24\% vs. 9.8\%).(17) Distinct study populations and methods limit the comparability of estimates.

The diagnostic criteria established by ATS/IDSA in 2007 for NTMLD ${ }^{(11)}$ are the most used for therapeutic decision making and were met by $74 \%$ of the patients in the present study. Those criteria could not be wholly applied, because our sample included HIV-positive patients with low CD4 counts and severe respiratory symptoms, requiring immediate therapeutic intervention; in addition, there were symptomatic cases with radiologic findings in which we were unable to obtain a second sputum sample for the identification of the mycobacteria because of scarce sputum production. Also, some patients who were already on treatment were referred from other institutions without that identification.

Regarding cure, in addition to other factors, therapeutic success depends on the species that cause the lung disease: in our study, patients who

Table 3. Nontuberculous mycobacterium species identified in the patients with nontuberculous mycobacterial lung disease according to their HIV status $(\mathrm{N}=100)$.

\begin{tabular}{lcccc}
\multicolumn{1}{c}{ Species } & HIV + & HIV - & HIV? & n \\
M. avium & 15 & 6 & 5 & 26 \\
M. intracellulare & 7 & 0 & 2 & 2 \\
M. kansasii & 12 & 3 & 5 & 17 \\
M. abscessus & 7 & 0 & 0 & 12 \\
M. fortuitum & 4 & 0 & 1 & 4 \\
M. gordonae & 2 & 0 & 0 & 3 \\
M. simiae & 1 & 0 & 0 & 1 \\
M. szulgai & 2 & 0 & 3 & 2 \\
Unidentified NTM & 8 & 15 & & 26 \\
\hline
\end{tabular}

NTM: nontuberculous mycobacteria; and HIV?: HIV status not informed.

Table 4. Clinical and epidemiological studies about nontuberculous mycobacterial lung disease in Brazil.

\begin{tabular}{|c|c|c|c|c|c|c|c|}
\hline Author & $\begin{array}{l}\text { Brazilian } \\
\text { state }\end{array}$ & Period & Patient, $\mathbf{n}$ & $\begin{array}{c}\text { Male } \\
\text { gender, \% }\end{array}$ & $\begin{array}{c}\text { Mean } \\
\text { age, } \\
\text { years }\end{array}$ & Predominant species & $\begin{array}{c}\text { Met the } \\
\text { criteria } \\
\text { for } \\
\text { NTMLD }\end{array}$ \\
\hline $\begin{array}{l}\text { Matos } \\
\text { et al. }{ }^{(23)}\end{array}$ & Bahia & $1998-2003$ & 19 & 68.4 & 48.8 & $\begin{array}{c}\text { M. chelonae/M. abscessus/ } \\
\text { MAC/M. kansasii }\end{array}$ & $14(74.4)$ \\
\hline $\begin{array}{l}\text { Fusco da } \\
\text { Costa } \\
\text { et al. }{ }^{(25)}\end{array}$ & Pará & $2010-2011$ & 38 & 27.6 & 52 & $\begin{array}{l}\text { M. massiliense/M. } \\
\text { avium/M. intracellulare }\end{array}$ & $29(76.3)$ \\
\hline $\begin{array}{l}\text { Lima } \\
\text { et al. }{ }^{(24)}\end{array}$ & Rondônia & $2008-2010$ & 45 & 64.5 & 50 & $\begin{array}{c}\text { M. abscessus/M. avium/M. } \\
\text { fortuitum }\end{array}$ & $19(46.7)$ \\
\hline $\begin{array}{l}\text { de Mello } \\
\text { et al. }{ }^{(17)}\end{array}$ & $\begin{array}{l}\text { Rio de } \\
\text { Janeiro }\end{array}$ & $1993-2011$ & 174 & 72.1 & 55 & $\begin{array}{c}\text { M. kansasii/MAC/M. } \\
\text { abscessus }\end{array}$ & $101(58)$ \\
\hline $\begin{array}{l}\text { Present } \\
\text { study }\end{array}$ & $\begin{array}{l}\text { Rio Grande } \\
\text { do Sul }\end{array}$ & 2003-2013 & 100 & 51.0 & 54.6 & $\begin{array}{c}\text { MAC'M. kansasii/M. } \\
\text { abscessus }\end{array}$ & $74(74.0)$ \\
\hline
\end{tabular}

NTMLD: nontuberculous mycobacterial lung disease; and MAC: Mycobacterium avium complex.

avalues expressed as $n(\%)$. ${ }^{b}$ In accordance with Griffith et al.(11) 
met the ATS/IDSA criteria and were infected with MAC had a cure rate of $60.7 \%$. Since rifampin started to be included in regimens, $M$. kansasii has become one of the most treatable causes of NTMLD. ${ }^{(3)}$ In the present study, the cure rate of those infected with $M$. kansasii was $73.3 \%$. The study by de Mello et al. ${ }^{(17)}$ presented similar results for MAC (57.8\%) and $M$. kansasii (71.4\%) infections. The patients infected with $M$. abscessus met stability criteria in $70 \%$ of the cases. Lung disease caused by $M$. abscessus is difficult to treat; in some cases, complete cure of the disease cannot be achieved, and, therefore, clinical improvement is a more viable target, which is considered a favorable outcome for these patients. ${ }^{(11)}$ In our sample, approximately $80 \%$ of rapidly growing mycobacteria isolates were identified as $M$. abscessus.

Another limitation of our study, which is an obstacle in the treatment of NTMLD, was the impossibility of performing susceptibility tests, which would help select the most appropriate treatment regimen for our patients. (11) Molecular identification of NTM species and susceptibility testing were not performed in our center, and the samples had to be sent to the Brazilian referral center in Rio de Janeiro. The molecular identification results were available at least two months later.
In Brazil, there are few studies about NTMLD, making it difficult to know its prevalence in the country. Most studies deal with NTM isolates, not with the prevalence of the disease. Table 4 shows a review of studies regarding NTMLD published in Brazil. Despite the shortage of data, MAC, M. kansasii, and M. abscessus are the most prevalent species in all studies available.

The lack of differentiation between $M$. tuberculosis and NTM makes the problem even more complicated. It is essential to know the specific etiology of the lung disease and its associated conditions in order to establish the appropriate treatment, considering the fact that each species requires a specific treatment regimen. Therefore, it is essential that culture, molecular identification, and susceptibility testing should be performed for all suspected NTMLD cases and that the reporting of NTMLD be mandatory so that the patients can be properly treated and the actual prevalence of the disease can be determined in Brazil.

\section{ACKNOWLEDGMENTS}

The authors would like to thank the staff of the Hospital Sanatório Partenon and the Instituto de Pesquisas Biológicas, Laboratório Central de Saúde Pública do Rio Grande do Sul.

\section{REFERENCES}

1. Tortoli E. Impact of genotypic studies on mycobacterial taxonomy: the new mycobacteria of the 1990s. Clin Microbiol Rev. 2003;16(2):31954. https://doi.org/10.1128/CMR.16.2.319-354.2003

2. Halstrom S, Price $P$, Thomson R. Review: Environmenta mycobacteria as a cause of human infection. Int J Mycobacteriol. 2015:4(2):81-91. https://doi.org/10.1016/j.ijmyco.2015.03.002

3. Weiss $\mathrm{CH}$, Glassroth J. Pulmonary disease caused by nontuberculous mycobacteria. Expert Rev Respir Med. 2012;6(6):597-612; quiz 613 https://doi.org/10.1586/ers.12.58

4. Sexton $P$, Harrison AC. Susceptibility to nontuberculous mycobacterial lung disease. Eur Respir J. 2008;31(6):1322-33 https:// doi.org/10.1183/09031936.00140007

5. Adjemian J, Olivier KN, Seitz AE, Holland SM, Prevots DR. Prevalence of nontuberculous mycobacterial lung disease in U.S. Medicare beneficiaries. Am J Respir Crit Care Med. 2012;185(8):881-6. https:// doi.org/10.1164/rccm.201111-20160C

6. Kennedy MP, O'Connor TM, Ryan C, Sheehan S, Cryan B, Bredin C. Nontuberculous mycobacteria: incidence in Southwest Ireland from 1987 to 2000. Respir Med. 2003;97(3):257-63. https://doi. org/10.1053/rmed.2003.1431

7. Freeman J, Morris A, Blackmore T, Hammer D, Munroe S, McKnight $\mathrm{L}$. Incidence of nontuberculous mycobacterial disease in $\mathrm{New}$ Zealand. N Z Med J. 2007;120(1256):U2580

8. Hernández-Garduño E, Rodrigues M, Elwood RK. The incidence of pulmonary non-tuberculous mycobacteria in British Columbia, Canada. Int J Tuberc Lung Dis. 2009;13(9):1086-93.

9. Daley $\mathrm{CL}$, Griffith DE. Pulmonary non-tuberculous mycobacterial infections. Int J Tuberc Lung Dis. 2010;14(6):665-71.

10. Shenai S, Rodrigues C, Mehta A. Time to identify and define nontuberculous mycobacteria in a tuberculosis-endemic region. Int $\mathrm{J}$ Tuberc Lung Dis. 2010;14(8):1001-8.

11. Griffith DE, Aksamit T, Brown-Elliott BA, Catanzaro A, Daley C, Gordin F, et al. An official ATS/IDSA statement: diagnosis, treatment and prevention of nontuberculous mycobacterial diseases. Am J Respir Crit Care Med. 2007;175(4):367-416. https://doi.org/10.1164/ rccm.200604-571ST

12. Wildner LM, Bazzo ML, Liedke SC, Nogueira CL, Segat G, Senna $S G$, et al. Mycobacteria mobility shift assay: a method for the rapid identification of Mycobacterium tuberculosis and nontuberculous mycobacteria. Mem Inst Oswaldo Cruz. 2014;109(3):356-61. https:// doi.org/10.1590/0074-0276130458
13. Brasil. Ministério da Saúde [homepage on the Internet]. Brasilia: o Ministério: 2016c [cited 2018 Jan 16]. Saúde de A a Z-Orientações para profissionais de saúde [about 6 screens]. Available from: http:// portalms.saude.gov.br/saude-de-a-z/tuberculose/orientacoes-paraprofissionais-de-saude

14. Taylor TB, Patterson C, Hale Y, Safranek WW. Routine use of PCRrestriction fragment length polymorphism analysis for identification of mycobacteria in liquid media. J Clin Microbiol. 1997;35(1):79-85.

15. Brunello F, Ligozzi M, Cristelli E, Bonora S, Tortoli E, Fontana R. Identification of 54 mycobacterial species by PCR-restriction fragment length polymorphism analysis of the hsp65 gene. J Clin Microbiol. 2001;39(8):2799-806. https://doi.org/10.1128/ JCM.39.8.2799-2806.2001

16. Brasil. Ministério da Saúde. Secretária de Vigilância à Saúde Perspectivas brasileiras para o fim da tuberculose como problema de saúde pública. Brasília: o Ministério. Boletim Epidemiológico. 2016;47(13):1-15

17. de Mello KG, Mello FC, Borga L, Rolla V, Duarte RS, Sampaio EP et al. Clinical and therapeutic features of pulmonary nontuberculous mycobacterial disease, Brazil, 1993-2011. Emerg Infect Dis. 2013;19(3):393-9.

18. Haas MK, Daley CL. Semin Respir Crit Care Med. 2016;37(2):230-42. https://doi.org/10.1055/s-0036-1572559

19. Brasil. Ministério da Saúde. Secretária de Vigilância à Saúde. AIDS e DSTs. Boletim Epidemiológico. 2015; Ano IV(1).

20. Prevots DR, Shaw PA, Strickland D, Jackson LA, Raebel MA, Blosky $M A$, et al. Nontuberculous mycobacterial lung disease prevalence at four integrated health care delivery systems. Am J Respir Crit Care Med. 2010;182(7):970-6. https://doi.org/10.1164/rccm.201002 03100C

21. Jing $H$, Wang $H$, Wang $Y$, Deng $Y$, Li $X$, Liu $Z$, et al. Prevalence of nontuberculous mycobacteria infection, China, 2004-2009. Emerg Infect Dis. 2012;18(3):527-8. https://doi.org/10.3201/eid1803.110175

22. O'Brien DP, Currie BJ, Krause VL. Nontuberculous mycobacteria disease in northern Australia: a case series and review of the literature. Clin Infect Dis. 2000;31(4):958-67. https://doi.org/10.1086/318136

23. Matos ED, Santana MA, de Santana MC, Mamede P, de Lira Bezerra $B$, Panão ED, et al. Nontuberculosis mycobacteria at a multiresistant tuberculosis reference center in Bahia: clinical epidemiological aspects. Braz J Infect Dis. 2004;8(4):296-304. https://doi.org/10.1590/ S1413-86702004000400005 
24. Lima CA, Gomes HM, Oelemann MA, Ramos JP, Caldas PC, Campos CE, et al. Nontuberculous mycobacteria in respiratory samples from patients with pulmonary tuberculosis in the state of Rondônia, Brazil. Mem Inst Oswaldo Cruz. 2013;108(4):457-62. https://doi.org/10.1590/S0074-0276108042013010

25. Fusco da Costa AR, Falkinham JO 3rd, Lopes ML, Barretto AR, Felicio JS, Sales LH, et al. Occurrence of nontuberculous mycobacterial pulmonary infection in an endemic area of tuberculosis. PLoS Negl Trop Dis. 2013;7(7):e2340. https://doi.org/10.1371/journal. pntd.0002340

26. Prevots DR, Marras TK. Epidemiology of human pulmonary infection with nontuberculous mycobacteria: a review. Clin Chest Med 2015;36(1):13-34. https://doi.org/10.1016/j.ccm.2014.10.002

27. Christensen EE, Dietz GW, Ahn CH, Chapman JS, Murry RC, Anderson $\mathrm{J}$, et al. Initial roentgenographic manifestations of pulmonary Mycobacterium tuberculosis, $M$ kansasii, and $M$ intracellularis infections. Chest. 1981;80(2):132-6. https://doi. org/10.1378/chest.80.2.132

28. Koh WJ, Kwon OJ, Lee KS. Nontuberculous mycobacterial pulmonary diseases in immunocompetent patients. Korean J Radiol. 2002;3(3):145-57. https://doi.org/10.3348/kjr.2002.3.3.145 